\title{
Anísio Teixeira e a educação integral ${ }^{1}$
}

\author{
Ana Maria Cavaliere ${ }^{2}$ \\ Universidade Federal do Rio de Janeiro, Rio de Janeiro-RJ, Brasil
}

\begin{abstract}
Resumo: A concepção de educação integral, ancorada na extensão do tempo escolar, esteve sempre presente na obra de Anísio Teixeira. Partindo de uma justificativa, em 1930, ainda em parte baseada no espírito higienista-educacional, chega, em 1950, a uma proposta de educação escolar emancipadora de indivíduos e nação. Este texto apresenta a ideia de que a defesa da educação integral pelo autor passou por momentos diversos, mas conduziu o desenvolvimento de seu pensamento em relação a temas como alfabetização das massas, fim do dualismo escolar e qualidade da educação popular, mantendo-se como premissa ao longo de sua obra.
\end{abstract}

Palavras-chave: educação, história da educação - Brasil, direito à educação, políticas públicas.

\section{Anísio Teixeira and the integral education}

\begin{abstract}
The conception of integral education, based on the idea of full-time schooling, had always been present in the work of Anísio Teixeira. Starting from a justification, in 1930s, still partly influenced by the hygienist-educational atmosphere, it introduces, in 1950s, the proposal of education as a condition to promote the nation and the individuals'emancipation. This article argues that Anísio Teixeira's defense of the integral education went through changes, but followed the development of his thought about themes such as mass alphabetization, end of school dualism, and the quality of popular education, which remained a philosophical premise throughout his work.
\end{abstract}

Keywords: education, history of education (Brazil), equal education, public policies.

\section{Anísio Teixeira y la educación integral}

Resumen: La concepción de la educación integral basada en la extensión del tiempo escolar estuvo siempre presente en la obra de Anísio Teixeira. En 1930, su justificativa residía en el espíritu higienista-educacional y en 1950 en una propuesta de educación escolar emancipadora de los individuos y de la nación. El trabajo argumenta que la defensa de la educación integral realizada por el autor ha pasado por momentos diversos pero acompañó su pensamiento en temas como alfabetización de las masas, dualismo escolar y calidad de la educación popular, manteniéndose como premisa a lo largo de toda su obra.

Palabras clave: educación, historia de la educación - Brasil, derechos a educación, políticas públicas.

No Brasil, a compreensão da maneira pela qual a concepção de educação integral se desenvolve passa obrigatoriamente pelo estudo do pensamento educacional das décadas de 20 e 30 do século XX. A educação integral, significando uma educação escolar ampliada em suas tarefas sociais e culturais, esteve presente nas propostas das diferentes correntes políticas que se delinearam naquele período. As correntes autoritárias e elitistas a encampavam com o sentido de ampliação do controle social e dos processos de distribuição criteriosa dos indivíduos nos segmentos hierarquizados da sociedade. $\mathrm{O}$ extremo dessa tendência expressou-se na concepção de educação integral da Ação Integralista Brasileira. Já as correntes liberais encampavam a educação integral com o objetivo de reconstrução das bases sociais para o desenvolvimento democrático, o qual só poderia se dar a partir de indivíduos intencionalmente formados para a cooperação e a

1 Este artigo é uma versão substancialmente modificada de um texto apresentado durante a VI Jornada de Pesquisadores do Centro de Filosofia e Ciências Humanas da Universidade Federal do Rio de Janeiro - CFCH/ UFRJ, realizada no Rio de Janeiro, RJ, em 2004.

2 Endereço para correspondência:

Ana Maria Cavaliere. Rua Paissandu, 228/804. Flamengo. CEP: 22.210-080.

Rio de Janeiro-RJ, Brasil. E-mail: anacavaliere@uol.com.br participação. Entre os liberais, destaca-se o nome de Anísio Teixeira, por sua significativa elaboração teórica e técnica, visando à ampliação das funções da escola e o seu fortalecimento como instituição.

Nas primeiras décadas do século XX, o entusiasmo pela educação escolar era um sentimento difundido e que perpassava diferentes orientações ideológicas. Por isso, podemos encontrar significados diversos para a concepção de educação integral, representando diferentes projetos políticos. Para a Ação Integralista Brasileira (AIB), transformada em partido em 1935, a educação integral envolvia o Estado, a família e a religião, postos em sintonia pela escola, numa intensiva ação educativa. Tendo a AIB sido criada como um movimento cultural, que pretendia ser mais do que um partido político, seus planos envolviam a criação de uma nova concepção política e filosófica de mundo, para a qual a escola teria papel fundamental. Em seus documentos doutrinários, pregava que a educação escolar das massas não se limitava à alfabetização, mas visava elevar o nível cultural da população envolvendo aspectos físicos, intelectuais, cívicos e espirituais da formação dos indivíduos. O movimento tinha como lema $a$ educação integral para o homem integral.

A ideia de uma educação regeneradora da moral social e individual era comum nas primeiras décadas do século, mas 
foram os Integralistas que assumiram, de forma mais convicta, o papel moralizador da educação. Os valores da educação Integralista eram sacrifício, sofrimento, disciplina e obediência. Cumprir os compromissos, obedecer aos superiores, propagar sua doutrina e morrer pelos ideais eram as bases da atitude Integralista a ser inculcada.

Tal modelo de educação, ainda que apregoasse a formação do homem integral, submetia as diversas dimensões do processo educativo ao Estado, este sim o principal norteador da educação, a qual deveria estar a serviço de seus projetos e necessidades (Cavalari, 1995). O indivíduo seria moldado para servir aos interesses do Estado Integral. Ao mesmo tempo, a pretendida identificação entre os interesses do Estado, da família e da religião abria espaços para o privatismo. No contexto da grande discussão ocorrida nos anos 1930 entre católicos e defensores do ensino laico e público, os Integralistas tinham posição clara dentre os primeiros. Ainda que os Integralistas se referissem, em documentos, ao ensino unificado e gratuito para os graus primário e secundário, a defesa dos direitos da família e da religião os opunha à concepção radical de ensino público.

A educação integral tinha, para Integralistas, o sentido básico de ação doutrinária, posto que entendiam formação como um processo de conversão a uma verdade já estabelecida. Em síntese, eram a concepção doutrinária e, dentro dela, a incorporação da dimensão religiosa à educação escolar as características específicas da educação integral, tal como a entendia o movimento Integralista.

Em campo oposto ao exemplo da corrente autoritária brasileira, encontram-se, em âmbito internacional, as propostas de educação integral dos socialistas utópicos que, desde o século XIX, a tinham como bandeira política (Gallo, 1995). Além delas, destacam-se também as correntes liberais, representadas pelo diversos movimentos de renovação da escola, que viam, na educação integral, o meio de propagação da mentalidade e das práticas democráticas. A proposta de educação integral esteve, portanto, presente em diferentes campos políticos e servindo a múltiplas orientações ideológicas.

Foi buscando compreender a concepção liberal de educação integral, desenvolvida no Brasil, no contexto do movimento de renovação da escola da primeira metade do século $\mathrm{XX}$, que se nos fez obrigatória a visita à obra de Anísio Teixeira.

A importância e alcance do legado intelectual desse autor atingem diferentes aspectos da educação e do pensamento social brasileiro. A ampliação das funções da escola constitui uma de suas preocupações recorrentes e, diríamos mesmo, um dos pilares de seu pensamento educacional, perpassando todas as realizações que efetivou, particularmente no campo da escola elementar. Neste trabalho, analisamos especialmente três de seus livros, a saber, Educação para a democracia (Teixeira, 1997), Educação não é privilégio (Teixeira, 1994) e Educação é um direito (Teixeira, 1996).

\section{Os anos 1920 e 1930: a educação integral como renovação da escola}

As bases de uma concepção de educação escolar que alcançasse áreas mais amplas da cultura, da socialização primária, da preparação para o trabalho e para a cidadania estavam presentes desde os primórdios do percurso de Anísio Teixeira como pensador e político. Essa concepção foi sendo desenvolvida e aperfeiçoada por toda a sua obra e envolveu diversos elementos, entre eles a sua permanente defesa do aumento da jornada escolar discente nos diferentes níveis de ensino.

No entanto, é preciso notar que, embora a ideia de uma educação escolar abrangente esteja presente em toda a obra de Anísio Teixeira, o autor não faz uso da expressão "educação integral", talvez por não considerá-la suficientemente precisa e, provavelmente, para evitar qualquer identificação com os Integralistas, que, como vimos, usaram abundantemente, durante os anos 1930, as expressões "homem integral", "Estado integral" e "educação integral".

Quando ainda iniciante no campo da educação, como diretor da Instrução Pública do Estado da Bahia, Anísio Teixeira realizou, em 1927, sua primeira viagem aos EUA. Nessa viagem, assistiu a cursos na Universidade de Columbia e visitou instituições de ensino, lá permanecendo por sete meses. No ano seguinte, 1928, voltou aos EUA para aprofundar seus estudos, com vistas ao diploma de Master of Arts da Universidade de Columbia. Durante o curso, Anísio Teixeira tomou contato com as obras de John Dewey e W. H. Kilpatri$\mathrm{ck}$, as quais marcaram fortemente sua formação e lhe deram as bases teórico-filosóficas para a construção de um projeto de reforma para educação brasileira.

Após o retorno ao Brasil, Anísio Teixeira passou a desenvolver, gradativamente, com base no pragmatismo americano, uma concepção de educação escolar ampliada, que, ainda hoje, ecoa no pensamento e nos projetos educacionais que buscam o aprofundamento no caráter público da educação escolar. Durante todo o seu percurso como administrador e como intelectual, permaneceu fiel à visão de educação escolar que procurou reinventar, tendo como referência e finalidade a realidade educacional brasileira.

De onde partiu Anísio Teixeira para essa reinvenção? Quando de sua viagem aos EUA, já deixou em andamento uma reforma no sistema educacional da Bahia (Lei ${ }^{\circ} 1.846$ / 1925) na qual a influência de ideias renovadoras já era perceptível, ainda que predominasse o sentido republicanodemocratizador. Esse sentido, eminentemente político, era característico da época (Nagle, 1974) e esteve presente nas diversas reformas ocorridas nos sistemas públicos estaduais de educação, a partir de 1920, tais como a de São Paulo, com Sampaio Dória em 1920, a do Ceará, com Lourenço Filho, em 1922, a da Bahia, com Anísio Teixeira, em 1925, e a de Minas Gerais, com Francisco Campos em 1926. Essas reformas romperam com a estagnação nas políticas educacionais da República e se caracterizaram pela chegada à área 
educacional de uma efetiva preocupação com a expansão da escolarização. $\mathrm{O}$ discurso republicano começou a adquirir maior concretude e surgiram, nos estados, as políticas que poderiam conduzir ao processo de escolarização em massa da população brasileira. As reformas estaduais, além da preocupação com a ampliação das vagas, tenderam, no decorrer dos anos 20, a também incorporar uma concepção de escola com tarefas e responsabilidades sociais ampliadas. Nas palavras de Nagle (1974, p. 190), deu-se entre os anos de 1920 e 1929:

a ampliação da rede escolar, o melhoramento das condições de funcionamento das instituições escolares existentes, a criação de novas instituições, até mesmo de caráter paraescolar - com o que se estende o raio de ação da escola e novas funções lhe são atribuídas.

As consequências do processo de urbanização e industrialização, a crescente, e cada vez mais visível, desigualdade social e as mazelas dela decorrentes geraram nesse período, de maneira generalizada na intelectualidade e na classe política, um forte apelo pela valorização e pela transformação da educação escolar. O ingresso de Anísio Teixeira no campo educacional foi marcado por um movimento crítico a um sistema que dava mostras evidentes de inoperância, bem como pelas primeiras ideias renovadoras, chegadas ao Brasil via diferentes áreas de estudo e diferentes autores, inicialmente europeus. Àquelas primeiras influências renovadoras somaram-se, ao final da década de 20, a americana, tendo sido Anísio Teixeira seu principal divulgador. A crítica e a renovação foram, portanto, os pontos de partida de suas atividades.

\section{Ambiguidades históricas}

Foi ainda nos anos 20 que se delinearam ambiguidades dentro das quais caminharam, por pelo menos mais três decênios - até a perda daquele vigoroso impulso reformista -, o pensamento liberal em educação e toda uma geração de especialistas. Ambiguidades que resultavam da coexistência contraditória entre (a) uma visão radicalmente liberal e um liberalismo elitista, ainda "curativo" e "domesticador" das classes populares; entre (b) a escola com funções formativas e culturais ampliadas e a escola meramente alfabetizadora; e entre (c) a busca da qualidade na educação e a urgência da expansão, isto é, a urgência do crescimento quantitativo dos sistemas escolares. A rigor, esses três pares antitéticos estão imbricados e irão orientar o caminho que seguiremos para identificar a gênese e o desenvolvimento, no Brasil e, particularmente, na obra de Anísio Teixeira, da concepção de educação integral.

\section{O elitismo cívico-higienista e a visão liberal}

No início dos anos 1920, predominava o espírito higienista-educacional, que tinha em Miguel Couto seu expoente.
Pretendia-se "libertar o povo da ignorância". A bandeira da alfabetização surgia como uma cruzada moral de salvação da nação, como a solução para todos os males. A compreensão da ignorância como doença, dos analfabetos como seres que "vegetavam", a formulação "povo-criança", a ser educado e preparado para transformar-se em "povo-nação", levavam a um projeto autoritário de educação escolar. O desenvolvimento e a radicalização dessa tendência autoritária conduziriam, anos mais tarde, às formulações educacionais do movimento Integralista, anteriormente aqui referidas, mas a ilusão de que a alfabetização e a escolarização tinham algo de milagrosas em si mesmas era, na década de 20, muito generalizada. Disciplina, higiene e alfabetização compunham as bases de uma visão política ainda muito indiferenciada e que correspondia a uma primeira resposta às necessidades de uma nova ordem econômica, modelada pela indústria e pela vida urbana (Gondra, 2003).

A contradição que foi se delineando, até se explicitar nos anos 1930, esteve entre essa abordagem sanitária do analfabetismo e da educação e a visão que chamaremos aqui de autenticamente liberal. Essa contradição apareceu de forma emblemática na expressão "pensar o Brasil", cunhada por Vicente Licínio Cardoso, que a propôs como lema para a sua geração e a utilizou como base em seus trabalhos durante os anos 1920 (Carvalho, 2000). Chamamos a atenção para o fato de que a expressão trazia em si um sentido dúbio, podendo o verbo "pensar" ser interpretado como "compreender" o Brasil - condição para transformá-lo - ou como "curar" o Brasil - da doença já diagnosticada e para a qual já se tinha o remédio.

As formulações de Anísio Teixeira sobre uma nova concepção de escola surgiram nesse contexto, mas passaram, logo em seguida, a ancorar-se no pensamento de Dewey. Esse pensamento trouxe mais substância filosófica às ideias renovadoras e o movimento de superação da visão cívico-sanitária tornou-se inevitável. A forma como o "americanismo" de Anísio Teixeira chocou-se com o diagnóstico de viés higienista e curativo e a repercussão que teve no pensamento educacional da época vêm sendo tema de estudos. Carvalho $(1988,2000)$ levanta a hipótese de que tenha sido justamente o americanismo de Anísio o responsável pelo deslocamento do modo dominante de conceber a educação e a causa educacional nesse período. Esse deslocamento se expressaria, por exemplo, na passagem do consenso em torno da bandeira da "alfabetização", e o conteúdo moralizador que ela continha, para os movimentos em favor de uma educação de caráter formativo mais amplo e efetivamente democrático.

Os pensamentos foram se diferenciando até a ruptura com a visão cívico-sanitária. Até ali, o conceito de educação como ajustamento estático a um ambiente fixo estava na base de todo o pensamento educacional brasileiro. Ao trazer, diretamente para o campo da educação, de forma sistemática, a filosofia pragmatista americana, Anísio Teixeira introduziu um elemento perturbador naquela lógica. $\mathrm{O}$ conceito 
deweyano da educação (Cunha, 1994) como um processo contínuo de crescimento e desenvolvimento, tendo como finalidade a maior capacidade de crescimento e desenvolvimento, não admitia a visão curativa moralizadora: não supunha um modelo já pronto a ser alcançado. Essa concepção de educação como vida e descoberta, e não como preparação ou conserto, impôs novas maneiras de organização cotidiana da experiência escolar e criou a necessidade de sua diversificação e ampliação

\section{Alfabetização e formação ampla}

A ideia de educação integral cresceu como uma espécie de contraponto, no interior do processo expansionista do sistema escolar público. O desafio da expansão esteve, inicialmente, associado estritamente à alfabetização. Tratava-se de alfabetizar em massa os brasileiros, de torná-los cidadãos através do acesso à leitura e à escrita.

A primeira grande reforma estadual do ensino - a reforma paulista de 1920 - caracterizou o momento (Cavaliere, 2003). Elaborada por Sampaio Dória, diretor da Instrução Pública do Estado, teve a questão da alfabetização como central. Suas principais medidas visavam ao crescimento rápido do número de alfabetizados no estado. Para isso, propôs a redução do ensino primário de quatro para dois anos. A obrigatoriedade, bem como a gratuidade, também foram circunscritas a esses dois anos de escolaridade. Quanto à jornada escolar, esta foi reduzida de quatro ou cinco horas para a metade disso. A solução da redução do tempo foi tecnicamente justificada com base na melhor qualidade do trabalho desenvolvido em tempo compacto e turmas seriadas (Dória, 1923).

Na reforma paulista de 20 , o pensamento predominante foi ainda o da alfabetização como panaceia. Isso gerou inúmeras críticas dos intelectuais da educação, que perceberam o equívoco de ter a alfabetização como um fim em si mesmo, sem um projeto de inserção educacional mais amplo e culturalmente consequente. Entre o grupo de profissionais da educação que despontava nas primeiras décadas do século XX, a solução de redução do número de anos e da jornada escolar no ensino primário foi entendida por muitos como um retrocesso para o ensino paulista da época.

À exceção da reforma paulista de 1920, a primeira do conjunto que se seguiu, todas as demais apresentaram em suas justificativas e regulamentos uma concepção de educação primária bastante ampliada. Como demonstrou Carvalho (1988), a partir de meados da década de 20 o "fetichismo da alfabetização" cedeu lugar aos movimentos em favor de uma concepção de educação integral.

Lourenço Filho era dos que propunham um tipo de escola que pretendia ir muito além da simples alfabetização. Como diretor-geral da Instrução Pública do Estado Ceará, entre os anos de 1922 e 1923, em entrevista concedida à época, reproduzida por Nagle (1974, p. 211) afirmava que
O ensino primário deve ser mais alguma coisa, as noções mais necessárias à vida, no ambiente que a criança terá que viver. Afinal de contas, ler e escrever não adianta nem atrasa a ninguém, se, na escola, não se dão outras noções que formem equilibradamente o espírito e informem para agir com inteligência, isto é, de modo a aproveitar as forças da natureza, na produção de riqueza geral e no conforto da vida

Mais adiante, em 1927, a reforma promovida no Distrito Federal por Fernando de Azevedo, apresentava no texto de seu "Regulamento do Ensino", citado por Nagle (1974, p. 213), o seguinte trecho:

A escola primária se organizará dentro desse espírito de finalidade social: a) como vestíbulo do meio social, para influir sobre ele, integrando as gerações na comunidade pela adaptação crescente da escola às necessidades do meio, prolongando sobre o lar a sua ação educativa e aparelhando-se para reagir sobre o ambiente, por um programa de educação moral que tenda ao desenvolvimento de qualidades e à reação contra defeitos dominantes no meio social; b) como verdadeira escola de trabalho para fim educativo ou escola comunidade, em que se desenvolve o sentido da ação, o gosto do trabalho manual, o sentimento de cooperação e o espírito de solidariedade social; c) para atrair e acolher, sem distinção alguma, crianças de todas as proveniências e contribuir eficazmente para atenuar e quebrar o sentimento isolador de diferenças sociais, criadas pelas diferenças de situações econômicas.

Em diversos momentos, Anísio Teixeira chegou a considerar perniciosa a alfabetização por si mesma e afirmava que "desacompanhado de educação, o miraculoso alfabeto, em verdade, só produz males” (Teixeira, 1997, p. 83).

A defesa de uma escola com funções ampliadas, visível nas reformas dos anos 1920, se aprofundou entre os intelectuais reformistas e apareceu no Manifesto dos Pioneiros da Educação Nova de 1932, documento elaborado por 26 intelectuais que propunha a renovação educacional do país.

Mas, do direito de cada indivíduo à sua educação integral, decorre logicamente para o Estado que o reconhece e o proclama o dever de considerar a educação, na variedade de seus graus e manifestações, como uma função social eminentemente pública, que ele é chamado a realizar, com a cooperação de todas as instituições sociais.

O termo "educação integral" aparece três vezes no texto do Manifesto, uma delas para contextualizar uma citação do poeta francês Lamartine, revolucionário de 1848 e defensor dessa concepção de educação. A ideia de educação integral presente no documento é a do direito do indivíduo a uma educação pública que alcance diversas dimensões de sua 
formação. Afirma o "direito biológico de cada indivíduo à sua educação integral" e defende a necessidade de a escola aparelhar-se de forma a "alargar os limites e o raio de ação". O texto utiliza ainda a expressão "formação integral das novas gerações". Sugere a criação de instituições periescolares e postescolares, de caráter educativo ou de assistência social, que deveriam ser incorporadas em todos os sistemas de organização escolar.

\section{A qualidade e o desafio da expansão}

Outro enfoque necessário à compreensão da gestão e do desenvolvimento da concepção de educação integral em Anísio Teixeira é o do embate entre a expansão e a manutenção da qualidade dos sistemas públicos. A formação do caminho histórico excludente entre a qualidade e a quantidade esboçouse ainda no decorrer dos anos 1920. Intelectuais e educadores enxergaram a impossibilidade de haver uma dissociação entre as duas dimensões e, em geral, recusaram a solução de ampliar a oferta de ensino às custas da redução do tempo de escola para cada criança. A partir dos debates em torno da reforma paulista citada, o tema adquiriu relevância e, em 1926, Almeida Júnior, José Escobar e Lourenço Filho questionaram, em pesquisa promovida pelo jornal $O$ Estado de São Paulo, os próprios termos em que estava formulada uma das questões da pesquisa "Educação integral para poucos ou educação simplificada para muitos? É válida a solução da redução do ensino primário?" Lourenço Filho respondeu afirmando que a melhor solução provisória seria aquela que tornasse mais fácil a execução posterior da solução definitiva, sem perda de nenhum elemento empregado ou conflito com os resultados já obtidos. A pesquisa foi posteriormente publicada por Fernando de Azevedo no livro Educação na Encruzilhada (n.d.).

Entretanto, o tipo de solução preconizada por Lourenço Filho na resposta ao inquérito jornalístico do "Estado de São Paulo" não foi o que se generalizou. A dicotomia contida na questão se instalou. As reformas dos anos 1920, em seu conjunto, não puderam efetivamente contrarrestar o movimento histórico de perda de qualidade. No campo das ideias, elas tiveram um importante papel no estabelecimento do consenso em torno da necessária ampliação do tempo da escolarização primária e da jornada diária do aluno. Seus projetos previam a reformulação dos programas, tornando-os mais diversificados, criando atividades extracurriculares e paraescolares e fazendo surgir uma nova concepção de educação escolar primária com grande responsabilidade social e grande amplitude de ação. A realização concreta das propostas teóricas e normativas, entretanto, ficou muito aquém das pretensões dos reformadores, gerando mudanças ainda bastante limitadas no sistema educacional.

Foi, portanto, durante as décadas de 20 e 30 que a bandeira da educação integral se desenvolveu, adquirindo consistência teórica, a partir do contato com o pensamento pragmatista americano, e sentido político, com o enfrentamento ao "fetichismo da alfabetização".

\section{A experiência do Distrito Federal}

Em 1931, Anísio Teixeira voltou a assumir cargo público na área educacional, tornando-se diretor da Instrução Pública do Distrito Federal no governo Pedro Ernesto.

Nesse período, em meio à atuação administrativa, reafirmaram-se as mais importantes vertentes de seu pensamento, inclusive a concepção ampliada de educação escolar. A laicidade e o fortalecimento do ensino público destacam-se em seu pensamento.

Em sua gestão no Distrito Federal, a constatação da evasão escolar e o inconformismo frente a ela foi um dos motores da ação de Anísio Teixeira. O autor apresentou diversos levantamentos de dados que demonstravam o fracasso da escola pública brasileira de então, ou seja, a enorme quantidade de crianças que eram dela excluídas. No Rio de Janeiro, em 1932, as 39.978 crianças do $1^{\circ}$ ano transformavam-se em 4.150 no $5^{\circ}$ ano. Esse era um de seus principais argumentos para contestar a qualidade da escola que se fazia no Brasil. Afirmava, ironicamente, que a escola primária, em seus últimos anos, "já entra a funcionar para o doutorado", ou seja, "são preparatórios para as chamadas faculdades, do mesmo modo porque o são os do curso secundário" (Teixeira, 1997, p. 80). Denunciou a finalidade restrita da escola elementar de preparar para a matrícula no ginásio e na faculdade e não de formar o indivíduo. Daí o alto índice de abandono.

A proposta de mudança dessa realidade teve, em seu cerne, as ideias de uma escola complexa e de que cabe a ela garantir que a civilização "feita pelo homem não o venha esmagar e destruir" (Teixeira, 1997, p. 85). Mas, afirmava o autor, tais objetivos renovadores da escola não são alcançáveis em curto prazo. Ainda tendo o "fetichismo da alfabetização" como pano de fundo, afirmava que depois de atingido o domínio da leitura, da escrita e das quatro operações,

resta toda a obra de familiarizar a criança com os aspectos fundamentais da civilização, habituá-la ao manejo de instrumentos mais aperfeiçoados de cultura e dar-lhes segurança de inteligência e de crítica para viver em um meio de mudança e transformação permanentes (Teixeira, 1997, p. 85).

Anísio Teixeira resumiu a realidade existente e justificou as mudanças necessárias a uma nova escola nos quatro itens que se seguem: (a) porque as transformações são tão aceleradas que as instituições mais naturais de educação - a família e a própria sociedade - não têm elementos para servir à situação nova, tornando-se preciso que a escola amplie as suas responsabilidades, assumindo funções para as quais bastavam, em outros tempos, a família e a sociedade mesmas, (b) porque o novo critério social de democracia exige que todos se habilitem não somente para os deveres de sua tarefa econômica, como para participar da vida coletiva, em todos os sentidos, devendo cada homem ter possibilidades para vir a ser um cidadão com plenos direitos na sociedade, 
(c) porque a ciência, invadindo o domínio da educação, criou a necessidade de reconstrução dos velhos processos de ensino e de ajustamento de novos materiais de instrução, (d) porque uma concepção nova esclareceu que educação não é simplesmente preparação para a vida, mas a própria vida em permanente desenvolvimento, de sorte que a escola deve-se transformar em um lugar onde se vive e não apenas se prepara para viver (Teixeira, 1997, p. 89).

Com base nesses quatro itens, procedeu à reorganização da Direção Geral da Instrução Pública do DF, que, pelo decreto $\mathrm{n}^{\circ} 3763$ de $1^{\circ}$ de fevereiro de 1932, criou 13 Inspeções Especializadas, entre elas, obras sociais escolares, periescolares e pós-escolares; educação de saúde e higiene escolar; educação física; música e canto orfeônicos. Criou ainda a Biblioteca Central de Educação, a Filmoteca e o Museu Central de Educação.

A medida implantava um aparelhamento que permitisse à educação escolar ampliar efetivamente seu raio de ação. No relato dessa reorganização, aparecia a grande preocupação com o ensino de música, artes, desenho, artes industriais, educação física e saúde, recreação e jogos, rompendo com a visão estritamente utilitária da educação escolar.

Ao descrever as inovações implantadas ou planejadas para a formação dos professores primários em nível superior, Anísio Teixeira destacava a necessidade da Escola de Educação vir a formar mestres especializados nas áreas de música, artes, desenho, artes industriais e domésticas, educação física e saúde, com a participação de outras unidades da Universidade do Distrito Federal (Teixeira, 1997, p. 206).

Em suas previsões do horário escolar, apresentou um plano que já continha a ideia da conjugação de escolas nucleares com os parques escolares, que viria a adotar, mais tarde, na Bahia e em Brasília, respectivamente nos anos 1950 e 1960. Nos quatro anos em que dirigiu a educação no Distrito Federal, colaborando com o governo progressista de Pedro Ernesto, realizou uma gestão inovadora. Nesse período, redigiu diversos textos, relatando suas ideias e feitos, nos quais apareceram, como veremos a seguir, inúmeras referências à concepção ampliada de educação escolar.

\section{Ideias e ações}

Os trechos citados no item anterior fazem parte da obra Educação para a Democracia, escrita entre os anos de 1931 e 1935, no período, portanto, da gestão do educador baiano no Distrito Federal. No livro, produzido em período de intensas realizações concretas, chama atenção o fato de que os textos sempre terminam com uma reflexão mais profunda sobre a condição do ser humano aprendiz, a correlação entre civilização e educação, o tipo de educação que favorece a democracia e a realização da condição humana da permanente aprendizagem.

A despeito do grande encantamento com as potencialidades da educação escolar, Anísio Teixeira não deixou de refletir e ponderar, nesse período, sobre os limites da mesma afirmando que "representa, realmente, uma observação superficial julgar que é a educação que produz a civilização. Confusão entre efeito e causa, conforme já acentuamos (...)" (Teixeira, 1997, p. 84).

Acrescenta que, no caso das sociedades que chama "em transição", como a brasileira,

começam a aparecer os fatores de progresso antes de os homens estarem preparados para eles, resultando daí uma transformação das funções da escola, que não poderá ser apenas perpetuadora dos costumes, hábitos e ideias da sociedade, mas terá de ser também renovadora, consolidadora e retificadora dos costumes, hábitos e ideias, que se vão introduzindo na sociedade pela implantação de novos meios de trabalho e novas formas de civilização (Teixeira, 1997, p. 85).

Fica claro que a escola pensada pelo autor para a sociedade brasileira tinha perfil instituidor, o qual estaria atrelado a vetores sociais mais amplos como, por exemplo, os novos meios de trabalho e os novos costumes.

Sua forte adesão à instituição escolar também não o impedia de ver a complementaridade entre casa e escola. Sobre a educação pré-escolar e a importância desse período para a vida dos indivíduos, desenvolveu longo raciocínio em que constatou o enfraquecimento da família devido à reconstrução social moderna. Segundo ele, a escola veio em socorro da família, cuja atuação primitiva e natural já não basta:

A escola ampliou os seus deveres até participar de todos os deveres do lar, assumindo a responsabilidade de dar às crianças todas as condições que lhe asseguram - ou lhe deviam assegurar - na família, a continuidade e a integridade de uma ação formadora completa. Educação e não instrução apenas. Condições de vida e não condições de ensino somente. Mas nem por isso a escola substitui integralmente o lar. Esse continuará e, para continuar, deve também ser refundido em suas bases intelectuais e sociais, como já o foi nas suas bases econômicas (Teixeira, 1997, p. 65).

Ainda que os textos de Educação para a Democracia expressem a adesão a uma concepção de educação integral e a superação da bandeira da alfabetização, é preciso ressaltar que a obra carrega ainda os ecos do pensamento que pretendeu superar. Conforme o autor foi aprofundando sua reflexão filosófica, a concepção de educação ampliada e as justificativas que para ela formula também foram se modificando. Podem-se encontrar, nos diversos capítulos e mesmo dentro de um mesmo capítulo, diferentes abordagens que revelam as mudanças teórico-filosóficas por que passava o pensamento do autor no período.

No capítulo "A educação pré-escolar", por exemplo, destaca-se uma compreensão ampliada da educação, e muito avançada para a época: 
A importância da educação, nos dias de hoje, não é apenas uma consequência da complexidade da vida moderna, porém, talvez ainda mais, da inclusão no seu campo de todas as questões da vida humana, que anteriormente possuíam técnicas ou setores diversos de ação (Teixeira, 1997, p. 67).

Mais adiante, no capítulo "A educação elementar e os seus objetivos", ressurge a marca de uma concepção funcionalista e reguladora da sociedade:

Só posso compreender a educação como o processo de preparação e distribuição de homens pelas diversas ocupações que caracterizam a vida humana, na atualidade. Três anos de escola elementar (...) não bastam para habilitá-los às ocupações corriqueiras, nem ao menos os preparam para fazer um pouco melhor o que terão que fazer de qualquer modo, mesmo levando a mais rudimentar das existências (Teixeira, 1997, p. 81).

E até mesmo o sentido moralista de "tratar o povo", isto é, dar a ele a educação necessária para que ele possa "civilizar-se":

a escola deve ensinar a todos a viver melhor, a ter a casa mais cuidada e mais higiênica; a dar às tarefas mais atenção, mais meticulosidade, mais esforço e maior eficiência; a manter padrões mais razoáveis de vida familiar e social; a promover o progresso individual, através os cuidados de higiene e os hábitos de leitura e estudo, indagação e crítica, meditação e conhecimento (Teixeira, 1997, p. 82).

Barreira (2000) considera que, em Anísio Teixeira, a ampliação das funções da escola, tomando para si tarefas que até então cabiam às famílias e a outras instituições, é um movimento que visa à equilibração social, e se encontra fundado em uma visão evolucionista, base do positivismo. Sem desconsiderar essa interpretação, é preciso lembrar que, segundo o mesmo autor, Anísio Teixeira trabalhava com a ideia de mudança de mentalidades dos indivíduos em geral e das elites como condição para a constituição da sociedade democrática.

A possibilidade de mudança de mentalidade está apoiada, em Anísio Teixeira, no pragmatismo deweyano, isto é, numa pretensão de que seja possível, nas vivências cotidianas, a reconstrução da experiência, para o que o protagonismo dos indivíduos é peça fundamental. Mesmo considerando-se que Anísio Teixeira concentrou expectativas excessivas nessa possibilidade, esse esperado protagonismo individual é elemento de antítese a uma organização social equilibrada e estável. O pragmatismo, diferentemente do pensamento marcado pelo positivismo, considera o pensamento reflexivo como fruto do enfrentamento com situações problemáticas e gerador, a cada momento, de formas momentaneamente mais adequadas e não padronizadas para enfrentar tais situações. Não haveria, portanto, uma linha de evolução necessária ou previsível (Amaral, 1990).

A dificuldade de lidar com a obra de Anísio Teixeira é justamente a sua constante espontaneidade. Essa espontaneidade permite que se enxergue o desenrolar de seu pensamento, não apenas ao longo de sua obra, mas dentro de cada texto, com suas idas e vindas e suas contradições.

No mesmo capítulo acima citado, pouco adiante, observa-se uma clara posição de base pragmatista:

A escola deve fornecer a cada indivíduo os meios para participar, plenamente, de acordo com as suas capacidades naturais, na vida social e econômica da civilização moderna, aparelhando-o, simultaneamente, para compreender e orientar-se dentro do ambiente em perpétua mudança que caracteriza esta civilização (Teixeira, 1997, p. 86).

A tônica de todos esses textos escritos no início da década de 1930 é a forte crença nas amplas potencialidades da educação escolar. Cada enfoque revela um aspecto diferente, que pode ser o papel socializador, o criador de cultura, o formador de indivíduos para a democracia, e todos recaem no necessário fortalecimento e enriquecimento da instituição escolar.

Segundo Nunes (2000), nesse período, o cultivo entre os agentes escolares do sentimento da escola enquanto instituição pública, assim como a concepção de Anísio Teixeira quanto à ampliação das elites, "incomodou a todos que, mesmo dentro das associações de educadores (...) defendiam um projeto repartido de educação" (p. 292).

\section{Os anos 1950 e 1960: a escola ampliada como antídoto à escola dual}

Após um período de afastamento da vida pública, que correspondeu à ditadura Vargas, Anísio Teixeira foi chamado, em 1946, a trabalhar na UNESCO, permanecendo em Paris por curto período para, logo em seguida, assumir o cargo de Secretário de Educação e Saúde da Bahia. O educador retomou sua ação política e intelectual com a mesma convicção no poder da escola que caracterizara sua prática nos anos 1930.

No texto "Educação não é privilégio", escrito em 1953, que integra o livro de mesmo nome (Teixeira, 1994), apresenta e desenvolve a concepção de educação escolar não especializada, não intelectualista, isto é, educação para a formação "comum" do homem. Defende a escola "pública" ou escola "comum" que se liga ao trabalho, à prática e à ciência que informa essa prática. É na caracterização de uma escola que deixa de ser da elite, na busca de uma nova política educacional que leve qualidade para a escola primária, que ele retoma e desenvolve sua concepção de educação escolar ampliada e defende o horário integral. 
Nessa retomada, o incremento do ingresso das classes populares no sistema escolar causava grande impacto e suas propostas tentavam responder a essa realidade. As crianças pertencentes a famílias não escolarizadas, sem intimidade com a linguagem escrita e a cultura escolar, não poderiam inserir-se num modelo de escola construído para as classes média e alta.

Ainda em "Educação não é privilégio" (1953), afirma que a escola primária, a qual tem um fim em si mesma e só secundariamente prepara para os níveis posteriores, não pode ser uma escola de tempo parcial, pois esta não será apenas uma escola de letras, mas de formação de hábitos de pensar e de fazer, de conviver e participar em uma sociedade democrática:

não se pode conseguir essa formação em uma escola por sessões, com os curtos períodos letivos que hoje tem a escola brasileira. Precisamos restituir-lhe o dia integral, enriquecer-lhe o programa com atividades práticas, dar-lhe amplas oportunidades de formação de hábitos de vida real, organizando a escola como miniatura da comunidade, com toda a gama de suas atividades de trabalho, de estudo, de recreação e de arte (Teixeira, 1994, p. 63).

Além da jornada escolar, a duração do ano letivo era motivo de atenção de Anísio Teixeira que, desde os anos 30, quando a carga horária anual da educação elementar era de cerca de 640 horas, afirmava ser esse número de horas absolutamente insuficiente, propondo 1080 horas, isto é, 180 dias de seis horas em média.

O tempo ampliado tornou-se uma necessidade prática imposta pela proposta educacional que defendia, ou seja, foi decorrência de sua concepção abrangente de educação escolar. Segundo o autor, para uma educação primária efetivamente pública, seria necessário (a) manter e não reduzir o número de séries escolares; (b) prolongar e não reduzir o ano letivo; (c) enriquecer o programa com atividades educativas, independentes do ensino propriamente intelectual; (d) preparar um novo professor para as funções mais amplas da escola:

sendo a escola primária a escola por excelência formadora, sobretudo porque não estamos em condições de oferecer a toda a população mais do que ela, está claro que, entre todas as escolas, a primária, pelo menos, não pode ser de tempo parcial. Somente escolas destinadas a fornecer informações ou certos limitados treinamentos mecânicos podem ainda admitir o serem de tempo parcial (Teixeira, 1994, p. 105).

Anísio Teixeira demonstrava muita clareza e segurança quanto ao fato de que, ao expandirem-se, as escolas passariam por necessárias modificações estruturais de programa, de métodos e de processos: a escola já não poderia ser a escola dominantemente de instrução de antigamente, mas fazer as vezes da casa, da família, da classe social e por fim da escola, propriamente dita, oferecendo à criança oportunidades completas de vida, compreendendo atividades de estudos, de trabalho, de vida social e de recreação e jogos (Teixeira, 1994, p. 162).

\section{O Centro Educacional Carneiro Ribeiro}

A solução dos prédios conjugados - as escolas-classe e as escolas-parque -, que garantiria a presença da criança na escola durante os dois turnos, aparece nos textos de Anísio Teixeira desde a década de 1930, em seus planos para a educação do Distrito Federal:

Haverá escolas nucleares e parques escolares, sendo obrigada a criança a frequentar regularmente as duas instalações. O sistema escolar para isso funcionará em dois turnos, para cada criança. Em dois turnos para crianças diversas de há muito vem funcionando. Daqui por diante será diferente: no primeiro turno a criança receberá, em prédio adequado e econômico, o ensino propriamente dito; no segundo receberá, em um parque-escola aparelhado e desenvolvido, a sua educação propriamente social, a educação física, a educação musical, a educação sanitária, a assistência alimentar e o uso da leitura em bibliotecas infantis e juvenis (Teixeira, 1997, p. 243).

Entretanto, foi em 1950, com o Centro Educacional Carneiro Ribeiro, que viria a detalhar e concretizar finalmente a ideia. Afirmou-se, na implantação do Centro, a profunda relação entre o prédio escolar e a qualidade do ensino na escola de horário integral.

O complexo educacional idealizado por Anísio Teixeira constava de quatro escolas- classe com capacidade para mil alunos cada, em dois turnos de quinhentos alunos, e uma escola-parque composta dos seguintes setores: (a) pavilhão de trabalho; (b) setor socializante; (c) pavilhão de educação física, jogos e recreação; (d) biblioteca; (e) setor administrativo e almoxarifado; (f) teatro de arena ao ar livre e (g) setor artístico. A escola-parque complementava de forma alternada o horário das escolas-classe, e assim o aluno passava o dia inteiro no complexo, onde também se alimentava e tomava banho. O Centro abrigava crianças dos sete aos 15 anos, divididas por grupos a princípio organizados pela idade cronológica. Previa-se a construção de residências para 5\% do total das crianças da escola, que fossem reconhecidamente abandonadas, e que ali viveriam (Éboli, 1983).

O Centro Carneiro Ribeiro tinha capacidade para quatro mil alunos, que lá permaneciam de $7 \mathrm{~h} 30$ às $16 \mathrm{~h} 30$. Anísio Teixeira pretendia construir ao todo nove Centros como esse, que lembrariam uma universidade infantil e ofereceriam às crianças um retrato da vida em sociedade. 
Na contramão da história da escola pública brasileira, que já percorria, àquela altura, o caminho do aligeiramento, o Centro era uma realização que simbolizava a posição de toda a obra teórica e prática de Anísio Teixeira, fazendo o papel de resistir ao que ele chamava de simplificação da escola pública.

A implantação do Centro Carneiro Ribeiro foi um momento de grande expectativa para o incansável espírito empreendedor de Anísio Teixeira. No discurso oficial da inauguração, relembrou a reforma paulista de 1920, criticando a concessão à perda de qualidade:

Foi, com efeito, nessa época que começou a lavrar, como ideia aceitável, o princípio de que, se não tínhamos recursos para dar a todos a educação primária essencial, deveríamos simplificá-la até o máximo, até a pura e simples alfabetização e generalizá-la ao maior número. A ideia tinha a sedução de todas as simplificações. Em meio como o nosso produziu verdadeiro arrebatamento. São Paulo deu início ao que se chamou de democratização do ensino primário. Resistiram à ideia muitos educadores. Resistiu a Bahia antes de 30. Resistiu o Rio, ainda depois da revolução. Mas a simplificação teve forças para congestionar as escolas primárias com os turnos sucessivos de alunos, reduzindo a educação primária não só aos três anos escolares de Washington Luís, mas aos três anos de "meios-dias", ou seja, ano e meio, até no grande São Paulo, aos três anos de "terços de dia", o que equivale realmente a um ano de vida escolar. Ao lado dessa simplificação na quantidade, seguiram-se, como não podia deixar de ser, todas as demais simplificações de qualidade (Teixeira, 1994, p. 173).

O projeto obteve grande destaque na imprensa baiana, recebendo críticas, em geral de oposicionistas, cuja tônica era a denúncia do estado precário em que se encontravam as demais escolas do Estado. Recebeu também elogios, principalmente aos aspectos arquitetônicos e pedagógicos, vindos inclusive de organismos internacionais (Almeida, 2001).

Em 1956, ocorreu, em Lima, uma reunião promovida pela Organização dos Estados Americanos com os ministros da educação da América Latina. Anísio identificou o início de um movimento de emancipação pela educação e lembrou que

a despeito das vozes, muito nossas conhecidas, dos que ainda julgam possível reduzir a educação popular, na América Latina, à mistificação das escolas primárias de tempo parcial e de curtos períodos anuais - a assembleia decidiu, com a afirmação de princípio da 'Declaração de Lima', por uma escola primária de seis anos de cursos e dias letivos completos (Teixeira, 1994, p. 78).
Trinta anos após seus primeiros contatos com o pragmatismo americano, a escola ampliada permaneceu na obra de Anísio Teixeira, então com um sentido político que ia além da ênfase no preparo adequado dos indivíduos para a vida em sociedade. Em sua caracterização, o autor explicitava a concepção de escola "comum" em oposição ao dualismo escolar. A educação comum, que alcançaria a todos em condições de igualdade, teria sentido socializador abrangente $\mathrm{e}$ democratizador da vida brasileira e somente poderia se realizar pela educação primária integral.

\section{As propostas de Anísio Teixeira para a LDB}

Em todo o processo de discussão que veio a desembocar na LDB de 1961, Anísio Teixeira teve posição ativa e de destaque. O Plano Nacional de Educação, dela decorrente, elaborado pelo Conselho Federal de Educação e aprovado em 1962, tinha entre suas metas qualitativas a instauração do dia completo para as duas últimas séries do ensino primário (ampliado então para seis anos). As $5^{\mathrm{a}}$ e $6^{\mathrm{a}}$ séries deveriam incluir em seu programa o ensino das artes industriais. $\mathrm{O}$ mesmo plano propunha ainda, para o ensino médio, o estudo dirigido e a extensão do dia letivo para seis horas de atividades, compreendendo estudo e práticas educativas. O ensino superior deveria contar com pelo menos $30 \%$ de alunos e professores de tempo integral.

Anísio Teixeira, que fora relator do Plano, apresentou parecer sobre as bases em que este deveria ser estabelecido. Elaborou ainda sugestões para que a articulação das instâncias federal, estadual e municipal garantisse aos serviços educacionais a necessária unidade, transformando-os nos mais importantes serviços públicos do país. Concebeu, para isso, um conjunto de escolas a constituírem o sistema nacional com as seguintes características:

a) um Centro de Educação em cada vilarejo de menos de 500 habitantes, compreendendo a escola primária (...); b) uma escola primária, organizada por séries em todas as localidades de mais de 500 até 1000 habitantes $(\ldots)$; c) escola primária de seis séries em todas as localidades de mais de 1000 até 2000 habitantes (...); d) centros Educacionais com escolas primárias de seis séries, escolas-parque e ginásio em todas as cidades de mais de 2000 até 5000 habitantes; e) escolas primárias de seis séries, escolas-parque, ginásios e colégios em todas as cidades de mais de 5000 habitantes; f) sistemas escolares completos em todas as capitais (Teixeira, 1994, p. 151).

Segundo o Plano, portanto, as localidades a partir de dois mil habitantes deveriam receber uma escola de tempo integral, por meio do sistema de escolas-classe e escolasparque.

No processo de debates e elaboração de propostas, a partir da aprovação da nova Lei, Anísio retomou a experiência 
que desenvolvera em Salvador, no Centro Carneiro Ribeiro e a defesa da educação primária integral, criticando, mais uma vez, os caminhos simplificadores que a escola pública assumira:

E a escola primária, reduzida na sua duração e no seu programa, e isolada das demais escolas do segundo nível, entrou em um processo de simplificação e de expansão de qualquer modo. Como já não era a escola da classe média, mas verdadeiramente do povo, que passou a buscá-la em uma verdadeira explosão da matrícula, logo se fez de dois turnos, com matrículas independentes pela manhã e pela tarde e, nas cidades maiores, chegou aos três turnos e até, em alguns casos, a quatro (Teixeira, 1994, p. 160).

Cabe ainda destacar que, no início dos anos 60, o sistema educacional da nova capital do país, Brasília, de cuja planificação Anísio Teixeira participou, foi organizado com base no modelo de Salvador, e pretendia ser uma referência para todo o país.

\section{A escola ampliada como doutrina}

Em toda a obra de Anísio Teixeira, que percorre cinco décadas, poderíamos listar diversas passagens que apresentam a defesa e a caracterização de uma escola de educação integral.

As bases sobre as quais o autor formulou sua concepção de educação integral são, resumidamente, o entendimento de que educação é vida e não preparação para a vida; o entendimento de que as demais instituições sociais perderam parte de suas capacidades educativas, que devem então ser supridas pela escola; e a busca da escola verdadeiramente "comum", isto é, democrática.

A concepção de educação integral de Anísio aprofundou-se com base no pragmatismo, na compreensão de que o homem se forma e desenvolve na ação, no fazer-se, e não por algum movimento exógeno de aprendizagem formal. Para além das concepções e movimentos políticos conjunturais, o grande diferencial do pensamento sobre educação escolar integral desenvolvido por Anísio deveu-se ao aprofundamento de seus fundamentos filosóficos, a partir, justamente, da filosofia social de John Dewey. Se o otimismo pedagógico estava difundido entre a intelectualidade brasileira das décadas de 20 e 30, Anísio Teixeira, em particular, se ancorava em um otimismo também filosófico, isto é, na expectativa de inexorabilidade do processo de integração social, presente na obra de Dewey (Cavaliere, 2002a). Isto the deu fôlego para persistir em seu projeto reformista até o início da década de 1960, quando novo período autoritário retirou-o, mais uma vez, da vida política.

Tanto na filosofia social de Dewey, como em todo o pensamento de Anísio, a questão da democracia é a questão crucial. A "reconstrução da experiência", ou seja, a possibilidade de os indivíduos viverem experiências que são, também, pensamento, é o elemento fundamental para a criação do modo de vida democrático. Somente uma escola que funcionasse como uma espécie de universidade para crianças e adolescentes poderia propiciar esse tipo de experiência.

Foi a associação entre o projeto republicano de educação pública e a teoria pragmatista da educação como reconstrução da experiência, ao lado da forte crítica ao sistema escolar vigente, que impulsionou a elaboração do projeto anisiano de educação integral. Analisando o conjunto e o percurso das referências à educação escolar ampliada, nas três obras estudadas neste texto, pudemos perceber diferentes ênfases nas justificativas desenvolvidas pelo autor.

De formulações nas quais ainda se encontravam presentes resquícios de uma visão moralizadora da educação, voltada para os indivíduos, no sentido de adequá-los a uma sociedade dada, o autor passou progressivamente para uma visão de educação integral que correspondia a uma clara definição estratégico-política de construção da sociedade democrática.

Percebemos, nessa análise, que a forte adesão de Anísio Teixeira à escola ampliada foi, provavelmente, uma adesão prévia, isto é, doutrinária. A convicção de Anísio Teixeira sobre o poder transformador da escola passou incólume por todas as mudanças, e fracassos, que presenciou. Esses fracassos não o encaminharam, por exemplo, às concepções estruturalistas e economicistas dos anos 60 que marcaram as interpretações sobre a relação entre sociedade e escola e enfraqueceram as expectativas sobre o poder transformador dessa última.

Em Educação é um direito (1996), publicado no emblemático ano de 1968, afirma que as teorias democráticas de liberdade individual e de laissez-faire do século XIX não eram efetivamente suficientes para a conjuntura a que se chegara, mas isso não o retira do marco do liberalismo igualitarista. Entendia por igualdade política a possibilidade de que todos os indivíduos tivessem acesso aos meios de vida do mundo contemporâneo, o que abriria caminho para a igualdade social. A escola, da forma como a imaginava, viabilizaria esse processo.

Mesmo se considerarmos que sua adesão à escola ampliada era uma espécie de a priori, a trajetória intelectual que cumpriu a reforçou ainda mais. É possível que parte de seu encantamento com o progressivismo deweyano fosse devido ao fato de que ele lhe possibilitaria permanecer e aprofundar sua elaboração apaixonada sobre uma escola fortalecida e socialmente instituinte.

Após seu afastamento da vida política, na ditadura militar iniciada em 1964, suas propostas, como o Centros Educacionais, não lograram continuidade. A concepção de educação integral esteve esquecida por cerca de 20 anos.

Nos anos 80 e 90, o programa dos CIEPs - Centros Integrados de Educação Pública do Rio de Janeiro se apresentou como uma espécie de aggiornamento da proposta de Anísio Teixeira. Há enormes convergências entre as duas propostas. 
Embora nos textos oficiais do Programa dos CIEPs (Ribeiro, 1986) apareçam incorporações de um discurso típico do materialismo histórico, como também do pensamento de Paulo Freire, a predominância, que se revela nos textos de Darcy Ribeiro, seu idealizador, e nas proposições concretas, segue de perto a tradição do pensamento de Anísio Teixeira. (Cavaliere, 2002b; Maurício, 2002). Foi principalmente através de Anísio Teixeira que a educação integral adquiriu a dimensão de alternativa generalizável, adequada ao mundo moderno, e não de mero treinamento intensivo, com vistas à adequação das populações "indisciplinadas" às novas exigências do sistema industrial urbano.

No Brasil do século XXI, surgiram inúmeros programas educacionais de governos estaduais e municipais que incorporam o conceito de educação integral. Em 2007, por meio da Portaria interministerial n.17, envolvendo os ministérios da Educação, da Cultura, do Desenvolvimento Social e Combate à Fome e do Esporte, foi lançado o programa Mais Educação, cujo objetivo é orientar recursos para "fomentar a educação integral de crianças, adolescentes e jovens, por meio de atividades sócio-educativas no contraturno escolar". Nesse momento em que ressurgem, nas políticas educacionais, a ideia e o conceito de educação integral, vale a pena revisitar a obra de Anísio Teixeira. A forma como o autor concebeu a educação integral e a escola de tempo integral é fonte imprescindível para uma abordagem do tema que se mantenha orientada pelo sentido de democratização da realidade educacional brasileira.

\section{Referências}

Almeida, S. B. (2001). A escola parque da liberdade, Bahia. In C. Monarcha (Org.), Anísio Teixeira: A obra de uma vida (pp.125-140). Rio de Janeiro: DP\&A Editora.

Amaral, M. N. C. P. (1990). Dewey: Filosofia e experiência democrática. São Paulo, Perspectiva/EDUSP.

Azevedo, F. (n.d.). A educação na encruzilhada. São Paulo: Melhoramentos.

Barreira, L. C. (2000). Escola e formação da mentalidade do desenvolvimento no discurso político-pedagógico de Anísio Teixeira. In M. L. B Smolka \& M. C. Menezes (Orgs), Anísio Teixeira: Provocações em educação (pp. 23-35). Campinas: Autores Associados.

Carvalho, M. M. C. (1988). Notas para a reavaliação do movimento educacional brasileiro (1920-1930). Cadernos de Pesquisa, 66, 4-11

Carvalho, M. M. C. (2000). O debate sobre a identidade da cultura brasileira nos anos 20: O americanismo de Anísio. In M. L. B Smolka \& M. C. Menezes (Orgs), Anísio Teixeira: Provocações em educação (pp. 53-69). Campinas: Autores Associados.

Cavalari, R. M. F. (1995). Educação e integralismo: Um estudo sobre estratégias de organização da ação integralista brasileira (1932-1937). Tese de doutorado não-publicada, Faculdade de Educação da Universidade de São Paulo, São Paulo.
Cavaliere, A. M. (2002a). Educação integral: Uma nova identidade para a escola brasileira. Educação e Sociedade, 23, 247-270.

Cavaliere, A. M. (2002b). Escolas de tempo integral: Uma idéia forte, uma experiência frágil In: A. M. Cavaliere \& L. M. C. Coelho (Orgs), Educação brasileira em tempo integral (pp. 93-111). Petrópolis: Vozes.

Cavaliere, A. M. (2003). Entre o pioneirismo e o impasse: A reforma paulista de 1920. Educação e Pesquisa, 29, 27- 44 .

Cunha, M. V. (1994). John Dewey, Uma filosofia para educadores em sala de aula. Petrópolis: Vozes.

Dória, S. (1923). Questões de ensino: Vol. 1. A reforma de 1920 em São Paulo. São Paulo: Monteiro Lobato \& Cia Editores.

Éboli, T. (1983). Uma experiência de educação integral. Rio de Janeiro: FAPERJ.

Gallo, S. (1995). Pedagogia do risco: Experiências anarquistas em educação. São Paulo: Papirus.

Gondra, J. G. (2003). Homo hygienicus: Educação, higiene e a reinvenção do homem. Cadernos CEDES, 23, 25-38.

Maurício, L. V. (2002). Permanência do Horário integral nas escolas públicas do Rio de Janeiro: No campo e na produção escrita. In Cavaliere, A. M \& Coelho, L. M. C. (Orgs.), Educação brasileira em tempo integral (pp. 112132). Petrópolis: Vozes.

Nagle, J. (1974). Educação e sociedade na primeira república. São Paulo: EPU/MEC.

Nunes, C. (2000). Anísio Teixeira: A poesia da ação. Bragança Paulista: EDUSP.

Ribeiro, D. (1986). O livro dos Cieps. Rio de Janeiro: Bloch.

Teixeira, A. (1994). Educação não é privilégio. Rio de Janeiro: Ed. UFRJ. (Original publicado em 1957)

Teixeira, A. (1996). Educação é um direito. Rio de Janeiro: Ed. UFRJ. (Original publicado em 1968)

Teixeira, A. (1997). Educação para a democracia. Rio de Janeiro: Ed.UFRJ. (Original publicado em 1936)

Ana Maria Cavaliere é Professora Adjunta da Faculdade de Educação da Universidade Federal do Rio de Janeiro, campus Praia Vermelha.
Recebido: 05/01/2009

$1^{a}$ revisão: 20/06/2009

Aceite final: 22/07/2009 